\author{
ANIA SADKOWSKA \\ Coventry University
}

KATHERINE TOWNSEND, TOM FISHER AND DAVID WILDE

Nottingham Trent University

\title{
(Dis-)engaged older men? Hegemonic masculinity, fashion and ageing
}

\begin{abstract}
Recently, we have witnessed an intensified interest from various fashion scholars on the subject of men and masculine identities. However, while most of the existing research initiatives explore various aspects of masculinity and fashion, they also seem to be limited in their choices of subjects to homosexual and/or young male adults. In this vein, Julia Twigg argues that older men remain 'largely disengaged from fashion as a cultural field' (2013a: 19). This article explores the nature of this theoretical disengagement when it comes to older heterosexual men's lived experience of fashion by drawing on in-depth, semi-structured interviews and personal inventories with a small sample of British men $(n=5)$ based in, or strongly linked to, Nottingham, United Kingdom. In-depth qualitative analysis of the research material revealed various contradictions displayed by the participants in relation to their ageing masculine identities and their often lifelong interest in fashionable clothing. We inspect these discrepancies from two perspectives in which such a disengagement might emerge: between men and fashion and between fashion and ageing. By analysing the findings through Connell's (2005) influential concept of hegemonic masculinity, we argue that some men both resist and reproduce such a stereotypical disengagement.
\end{abstract}

\section{KEYWORDS}

fashion clothing ageing mature men hegemonic masculinity disengagement 


\section{Introduction}

In recent years, we have witnessed an intensified interest from various fashion scholars in the subject of men and masculine identities with an accumulation of writing from Tim Edwards $(1997,2011)$ and the 2008 and 2009 Men's Fashion Readers (Reilly and Cosbey 2008; McNeil and Karaminas 2009) to name a few. But while most of these initiatives and commentaries explore various aspects of masculinity and fashion, they also seem to be limited in their consideration of homosexual and/or young male adults as subjects. In this vein, Julia Twigg argues that older men remain 'largely disengaged from fashion as a cultural field' (2013a: 19).

By analysing older men's relationships with clothing, in this article we call into question the nature of their disengagement from fashion, to show that some men both resist and reproduce such stereotypical disengagement. By drawing on in-depth, semi-structured interviews and personal inventories with a small and homogenous sample of British men, we analyse in depth these men's lived experiences of fashion. The focus of the study was on a particular fraction of mature men who all were white, British, heterosexual, middleclass and with a significant interest in their appearance through engagement with fashion and clothing. Furthermore, the men were all strongly linked to a particular geographical location, allowing us to obtain rich empirical material from a closely and purposively defined group of individuals for whom the research questions were significant and meaningful.

Similar to Kaiser et al. (2008), we interpret the individual men's accounts through Connell's (2005) influential concept of hegemonic masculinity. This is not a single pre-defined and fixed type of masculinity but it retains its hegemonic character though being in constant flux with its contestable characteristics depending on time and place; the hegemonic position is always entangled in various gender relations resulting in its different configurations. Connell's recognition of the body's significance in how masculinities are enacted and experienced is also relevant to this article, particularly, how it changes as men grow older. In this vein, we exploit the vantage point between the embodied experience of fashion (Entwistle 2000) and masculinity as ‘body-reflexive practices [that] involve social relations and symbolism' (Connell 2005: 64). In-depth exploration of the qualitative research material revealed various contradictions displayed by the participants in relation to their masculine identities, ageing bodies and their lifelong interest in fashionable clothing, which we present and analyse in relation to the participants' potential disengagement'from fashion as a cultural field' (Twigg 2013a: 19). In doing this, we separate and examine two ways in which such a disengagement might emerge: firstly, between men and fashion; and secondly, between fashion and ageing.

\section{Literature review}

\section{Fashion, clothing and men}

The term fashion denotes a complex, ambiguous and elusive concept encompassing a range of often interconnected and overlapping meanings. The range of fashion theories, from classical through to modern and postmodern theorists, does nothing to lessen the level of ambiguity for both academics and the general public; a clear delineation is lacking between fashion as a social process, an industrial system or indeed a form of material product. Consequently, many scholars (Wilson 1985; Crane 2012; Kaiser 2012) imply 
that juxtaposing various different perspectives from several disciplines can augment our understanding of what really constitutes fashion, an approach to which we subscribe to in this article.

Adopting such a multi-perspectival approach to understand fashion, sociologist Crane (2012) argues that there are four different types of fashion definitions based upon four aspects of how it is 'manifested'. In Crane's typology, the key word is 'manifestation', which can be understood as the practice of showing or embodying something abstract or theoretical. This is important for the present argument, because it highlights the intrinsic connection between 'fashion', 'manifestation' and 'appearance' but also 'representation' and 'agency', in the sense of making concepts that are hard to apprehend, like 'fashion', easier to grasp by intentionally and consciously making them visible in a certain way. Likewise, what is common in Crane's typology, and other mainstream fashion definitions, is that clothing functions as a primary form of its manifestation. Such conjunction, as Kawamura (2011: 9) argues, means the word 'fashion' often refers to 'clothing fashion' in the sense of the most popular and current clothing that the majority of individuals within given time and space adopt to wear. Consequently, in this article, we recognize various different ways of defining fashion, with our primary focus being on older men's engagement with clothing as a prime way of manifesting the materiality of their deliberate engagement, or not, with fashion (Klepp and Bjerck 2014).

In contrast to 'clothing', fashion often functions as a gendered concept, which is inextricably linked to women and femininity, and only occasionally extended to young and/or gay men (Cole 2000; Steele 2000; Arnold 2001; Breward 2010). In everyday discourse, men are somewhat excluded from active engagement with fashion, and their role in it is often reduced to passive observers of female engagement with it. In contrast, Reilley and Cosbey (2008: 3) comment that historically, it was menswear, rather than womenswear that 'has been decorative, impractical, erotic, changeable, revolutionary, idealistic, oppressive and restrictive, subject to strict protocols, and laden with meanings'. Hollander (1994) asserts that it was male dress that tended to lead the way for fashionable solutions. This history is important for the arguments presented in this article for two reasons. Firstly, it emphasizes that men's dress is always linked to its 'other', female counterpart (McNeil and Karaminas 2009), highlighting how strongly gendered the concept of fashion is. Repercussions of this linkage are clearly visible in the participants' narratives discussed in the article. Secondly, it indicates how rich the phenomenon of men's fashion is, albeit that it is often overlooked (Reilly and Cosbey 2008), resulting in rather distorted socio-cultural perceptions of the disconnection between men and fashion.

\section{Ageing and fashion}

What constitutes ageing and characterizes experience of being old differs between various cultural and historical contexts (Calasanti and Slevin 2006). Furthermore, even within a given time and space, the socio-cultural position of an ageing individual depends on a unique configuration of their embodied subject positions including their gender, class, ethnicity and the generation they belong to or identify themselves with (Kaiser 2012). Western cultures conflate beauty with youth and sexuality, assets particularly revered in fashion discourses. In contrast, ageing is tacitly equated with bodily deterioration and 
1. According to the UK Office for National Statistics (ONS 2011) the demographic post-Second World War baby boom applies to the peaked live births between the years 1946 and 1964 in United Kingdom loss of strength and beauty, resulting in the devaluation of it. Consequently, ageing tends to alienate individuals from engaging in and with fashion, potentially limiting if not precluding their clothing agency. An extreme example of this would be individuals in care homes whose clothing choices may be made by others rather than selected independently.

The bodily manifestations of growing older, such as greying hair, deepening wrinkles or changing physique are often reflected in one's, socially influenced, clothing choices (Twigg 2013b). Clothing may become what visibly differentiate older individuals from societal standards of beauty and may function as depicting if not stigmatizing those individuals (Lurie 1992; Chrisler and Ghiz 1993; Fairhurst 1998), influencing even further separation between the fields of fashion and ageing. Indeed, observing the contemporary clothing scene, with only few exceptions of fashion brands and designers, it can be concluded that ageing individuals might not only be given very little attention, but in fact their clothing agency can be actively limited by the little choice offered to them, often resulting in self-imposed exclusion.

However, it can also be argued that the disconnection between these two fields has recently weakened visibly (Twigg 2013b), evidenced by a growing presence of older models on fashion catwalks in advertising campaigns and the popularity of fashion blogs devoted to mature fashion. To add to this, an increasing number of scholars now recognize that fashion and clothing are an integral part of our everyday being, and that fashionable clothes are objects that inevitably must respond to the changing physicality of an ageing individual (Church Gibson 2000; Hurd Clarke et al. 2009; Twigg 2013a) as well as their aesthetic and functionality expectations (Sadkowska et al. 2015; Townsend et al. 2016). As a result of this, growing old and the experience of it in relation to fashion and clothing has become a significant topic in the contemporary research agenda (Sadkowska et al. 2015). Furthermore, within Western cultures, this can be linked to the current ageing of the post-Second World War baby-boomer generation, ${ }^{1}$ which, as Gilleard and Higgs (2000, 2005) argue, is responsible for the creation of a consumer culture built on youth and sexuality, as we know it today. This generation also coincided with an increased average lifespan and the development of an ageing population, which is significant for their potentially increased engagement with clothing.

However, even this expending fashion-ageing scholarship does not spread its interest equally across the gender spectrum. Arguably, many researchers influenced by the early feminist writings on ageing tend to focus on the somewhat more problematic position of older women and older gay men (Leontowitsch 2012), overlooking the ageing heterosexual man's relationship with fashion. The lack of attention on mature straight men might be a consequence of focus on groups that have easily been perceived as disadvantaged; however, older heterosexual men can also find themselves outside the contemporary norms of hegemonic masculinity, which tends to privilege youth and physical capacity. This situation creates the impression of a certain disconnection from fashion by the heterosexual subgroup of older men, pointing to a gap in current understanding to which this article responds.

It is also important to consider the historical context, and many scholars highlight the fact that men entering mid and later life in the United Kingdom in the early years of the twenty-first century, the British baby-boomer generation, have had very different fashion life courses compared with older or younger generations (Edwards 1997, 2011; Beynon 2002). In the United Kingdom, the years from the 1950s onwards were especially exuberant in 
terms of menswear, including the development of a variety of predominantly male-oriented youth subcultures, such as Mods and Rockers (Hebdidge 1979; Hall and Jefferson 1976), and the production of cheaper, mass-available fashion goods. Additionally, feminist movements since the Second World War worked to revise social perceptions of men and masculinities (Hearn 1995). All these socio-cultural developments have meant this generation witnessed and experienced significant changes in how masculinities, including hegemonic masculinities, were defined and, following Connell's (2005) argument, practiced.

\section{Situating the current article}

Although in this article we are not aiming to provide a comprehensive account of the historical emergence of men and masculinities as a field of study, it is important to remain aware of the social processes that can be seen to have played an important role in contemporary constructions of the terms involved. The brief consideration of historical perspectives provides an important benchmark to the narratives of our participants who grew up and developed their understandings of what it means to be a man, in a certain time and space (generational settings), and while they might be responsive to the changing social norms, at the same time they might still, intentionally or not, stay attuned to the generational knowledge inscribed on them regarding the most successful ways to do so.

Edwards (2006) discusses the emergence and development of critical studies of men and masculinities in terms of a three-phase model, and explains it in parallel to the three waves of feminist movements. According to him, the second wave of critical studies of men and masculinities arose in the 1980s as a direct critical response to the first wave, rejecting the sex role paradigm as ambiguous and limiting. At the same time, influenced by the social and cultural changes such as the advancement of consumer society, in which the consumption of fashion became prominent, and the rise of gay liberation movements, the concept of a natural and fixed 'masculinity' has been replaced by a more subtly inflected set of multiple and fluid 'masculinities' (Beynon 2002; Buchbinder 1994, 2012). The third wave of critical studies of masculinities has emerged under the strong influence of post-structural theory, and it has specifically analysed issues of gender in relation to theories of normativity, performativity and sexuality. Furthermore, such scholarship often embraces an interdisciplinary approach, though with a common thread of the significance of representation, and often in relation to the wider picture of change and continuity in terms of gender identities (Edwards 2006).

The various socio-cultural changes in regards to men and masculinities that the work referred to above has identified, that men can enact 'hybridized' or even 'bricolage' masculinities that not only are experienced differently depending on various times and situations but also comprise different versions of 'the masculine' (Beynon 2002). However, somewhat inevitably, among these multiple forms of masculinity, some are more respected than others as determined by their context, and a 'hegemonic masculinity' can therefore be defined as the most successful way of being a man in a given time and place (Connell 2005; Kimmel 1994). Hegemonic masculinity signifies exalted, yet culturally normative ideals of masculinity and impacts upon norms of social acceptance (Davis 2002; Pringle 2005). Riccierdelli et al. (2010) point out that hegemonic masculinity is (re-)produced via various discourses 
2. The interviews were conducted as a part of the first author's Ph.D. project on older individuals' experience of fashion and clothing (Sadkowska 2016) including appearance, sexuality, behaviours, occupations and, potentially, age. And while we may indeed, recognize different, often coexisting contemporary hegemonic masculinities (Cornwall and Lindisfarne 1994), they most often equate with white, muscular, straight, young/middle-aged and professionally successful men. In this vein, Spector-Mersel (2006: 68) implies that 'Western hegemonic masculinity scripts are concluded at middle age'. Consequently, while the age of the participants in this study puts them somewhat outside the current norms of hegemonic masculinity, they did enact it when they were younger, so the concept remains significant and influential when interpreting how they currently execute their ageing masculine identities.

By presenting the selected findings of an empirical study with five older British men, we now inspect the stereotypical assumption of older men's disengagement from fashion and interpret it in regards to the contemporary scripts of hegemonic masculinity outlined above; we focus on two ways in which such a disengagement might emerge: between men and fashion and between fashion and ageing.

\section{Methods}

The qualitative study involved in-depth, semi-structured, conversational interviews and personal inventories with five British men aged 54-632 (Table 1). For the personal inventories, the participants were asked to bring and talk about three to four fashion artefacts (clothing, accessories, textiles, photos, etc.) that had a special meaning to them. Three men were interviewed within the university settings, while two men were interviewed in their homes and invited the researcher to view the contents of their wardrobes, which generated additional research material, to which we refer in this article. All the participants were recruited via word of mouth and were white, heterosexual and middle class, with the majority living within Nottinghamshire, United Kingdom $(n=3)$, one participant living in Derbyshire, United Kingdom and one in Leicestershire, United Kingdom (but who were both personally and professionally linked to Nottingham).

The phenomenological approach to data analysis uncovers the richness of the research material and makes it possible to produce highly interpretative accounts that indicate the complexity of these men's relationship with fashion. However, the authors acknowledge that in line with the qualitative nature of Interpretative Phenomenological Analysis (IPA; Smith et al. 2009), this sample cannot be considered as representative of this demographic, and the findings are not generalizable.

\begin{tabular}{llll}
\hline Name $^{*}$ & Age & Occupation & County of residence \\
\hline Eric & 60 & Artist & Nottinghamshire \\
Grahame & 61 & Social care worker & Derbyshire \\
Henry & 54 & Academic & Leicestershire \\
Ian & 58 & Company director & Nottinghamshire \\
Kevin & 63 & Lecturer & Nottinghamshire \\
\hline
\end{tabular}

*Pseudonyms are used to preserve participants' anonymities.

Table 1: Sample characteristics 


\section{Findings \\ (Dis-)engagement I: Men and fashion}

The first type of disengagement that we explore in this article is that between men and fashion. As we have already discussed, across the field of fashion studies, the tendency exists to assume that fashion is a female domain. Despite recent work to expand the boundaries of fashion scholarship to include men and masculinities, Kaiser (2012: 136) argues that men's fashion remains'a space that is fraught with ambivalence and anxiety', and stereotypical men, especially older men are believed not to actively engage with fashionable clothing. However, as Twigg (2013b: 79) notes older men also 'wear clothes, buy garments in the market, and are subject to many of the cultural pressures that bear on women in relation to age', which implies that the apparent stereotypical disengagement of older men from fashion might not reflect how men actually experience it, and that some might diverge from such the scripts of performance. This study investigated the experiences of men who have exhibited a strong interest in fashion from their early childhood, as explained by Henry (54):

I consciously [...] sabotaged my school uniform. So my mother would say 'Oh, you can't wear that today'. And then I would put on my suit. And go to school in a suit. Because I thought that was suitable... rather than uhm... just wearing something else that was tatty. [...] But I used to work away at the seams... at the inside of the lining, to make them come apart. So I've always, at least since I was 9 or 10, been conscious of the clothes that I wore.

Here, Henry describes not only his interest in clothing, which started at an early age, but also certain limitations as to what he, as a young boy, could (or chose to) wear. He reveals the need he developed very early in his life to present himself differently than other boys, with clothing playing the role of a medium, which could actively differentiate him from others in his immediate environment. Similar accounts of achieving a certain uniqueness through fashion were present in narratives from all our participants, often linked to the generational subculture they belonged to and the historical events they witnessed and were part of.

In this vein, Eric (60) explained how important the feeling of being a member of the generation responsible for the development of youth culture and the phenomenon of 'youth fashion' has been for him and his continuing interest in fashion:

Being born in the [19]50s there was really nothing before that...'Teddy Boys' perhaps were the first to strike out and have their own sort of youth fashion but prior to that there was nothing and so it's a new learning, it's a new learning curve for all of us who were now, who were born then, who, $[\ldots]$ were influenced by fashion at the time and now... now we find ourselves nearly drawing pensions and thinking what? What now? Put a cardigan on and grey shoes? No. I'm dressing how I have always dressed really. [...] Is there a certain cut off age? Is there an age when you think: 'Oh, I can't possibly be involved in fashion now? I must get some old man kit and plod about in [...] (laughs) misshapen anoraks'. I know I'm not gonna do that [...] I guess that's where I am now. 
What is compelling in this extract is the clarity of the connection Eric makes between his fashion past and his current engagement with it. Arguably, this link between past and present can be extended to Eric's more general social attitude, touching upon a certain social resistance. When Eric was younger, he wore particular clothing to express his connection to specific youth subcultures and disconnection from contemporary older generations who were visibly less fashionable. However, when he himself becomes one of the older generations, he chooses clothing to express his resistance to being categorized as such. Eric openly resists wearing 'some old man kit' and 'misshapen anoraks' precisely because he associates that look with the older generations he witnessed in his youth and the generic fashion aesthetics applied to older men that he has no intention to imitate.

Because fashion has long been culturally associated with women and femininity, its discourses predominantly materialize in the lives of women. Arguably women, regardless their age, are more engaged with fashionable clothing than men; they invest more time and money in it than their male counterparts (Twigg 2013b). However, this should not be taken to indicate men's utter disengagement with fashion. As the above extracts show, the participants in this study exhibit strong, lifelong interests in fashionable clothing, often beginning in their childhood and developed and nurtured into their older years. Furthermore, our participants' investment in fashion and clothing was a common feature amongst their generation of men, which grew up witnessing various youth-oriented subcultures such as Teddy Boys, Mods or Punks, and who contributed to redefining the contemporary scripts of masculinity including clothing practices. To add to this argument, all participants equally strongly identified themselves with the first generation of educated and professionally successful men who simply had sufficient economic resources to actively engage with often expensive clothing. This, as discussed by Sadkowska et al. (2015), influenced them in developing a shared pioneering identity of the first generation of men who exhibited such distinctive traits in regards to their appearance, and consequently, the first generation of men who carried it into their older age. Alongside this acknowledgement of the distinctiveness of their generation, every participant in this study strongly related his interest in clothing to his unique and individual characteristics.

The richness of the research material shown above leads us to argue that a certain fraction of older men escapes the stereotypical assumption of their disengagement from fashion based on their gender identity. The participants in this study unequivocally exhibited a strong connection with fashion evidenced by their active engagement with clothing, from early childhood into their older age.

\section{(Dis-)engagement II: Fashion and ageing}

The second type of disengagement that we explore in this article is that between fashion and ageing. Here, we explore the stereotypical assumption that fashion, in general, is a sphere typically dominated by youth. Twigg (2013b) notices that in a 'high fashion' context ageing sets in as early as the late twenties. In this study, however, we are dealing with a'less specialized'idea of fashion than models on the catwalks. We focus exclusively on fashion as experienced by individuals on a daily basis as they wear, buy and otherwise engage with clothing. Within these research parameters, we set ageing to begin in late middle age, which leads to our focus on males aged 50 and 60 plus. This, as 
explained earlier, has a further significance when we consider related sociohistorical aspects including the characteristics of the baby-boomer generation, the development of youth culture and cheaper, mass-available fashion goods, and consequent acceleration of changes in fashion trends.

These shifts are also implicated in new, more appearance-conscious forms of masculinity - men's style and fashion magazines barely existed prior to the 1980s (Edwards 1997). Since then, however, this way of following changing fashion trends, once reserved exclusively for women, became widely available also to men. In the following extract, Ian (58) explains how such practice is no different for him now, nearly four decades after the first such publications appeared on the shelves:

I am always aware of what is going off... and I sort of have something at the back of my mind. Just by looking around and looking at magazines. I have something at the back of my mind that that is what is going to be... sort of very fashionable or something. Although I would not say I am very fashionable... at all. [...] [But] I read... certain magazines. Uhm... uhm... GQ - Gentleman Quarterly, and Esquire and magazines like that.

In this extract, Ian presents an interesting vision of himself as an individual who possesses a deep interest in fashion and pursues it further by engaging with media such as fashion magazines. Significantly, he points out that his awareness of changing fashions is not something that emerged artificially from his encounters with such magazines but, instead, it is something natural and organic to him, situated 'at the back of [his] mind', a phrase he used twice in this otherwise short extract.

Despite these arguably clear signs of his engagement with fashion, Ian distances himself from being categorized as a 'fashionable' man. This could be interpreted in two ways: firstly, Ian might indeed feel that, despite his knowledge and awareness of upcoming fashion trends, he is not able to keep up with these trends, perhaps for financial reasons. Hearn (1995) notices that men's experience of ageing is dominated by various forms of disengagement that are consequences of the decrease in their physical resilience, accompanied by changes in appearance, in parallel to changing roles, retirement or redundancy, which also might explain Ian's need to verbally emphasize his disengagement from fashion. However, the personal inventory conducted with Ian on the same day as the interview revealed the illusory character of this disengagement in his case, as he presented a whole array of various, often rather costly, garments, including designer brands such as Vivienne Westwood, Paul Smith and Jean Paul Gaultier. This suggests that Ian's note of reservation towards the word 'fashionable' may emanate from his feeling a certain unease about openly admitting how 'fashionable' man he really is, indicating a tension between who he really is and how he wants to present himself to the interviewer.

Alternatively, this unease could be simply an expression of Ian's modesty; however, we argue that it has a deeper basis and indicates his unwillingness to admit to being a fashionable older man and his need to create a superficial disconnection with fashion as a cultural field. Indeed, as an individual he does not associate himself with a vision of a 'fashionable man', in its conventional sense. However, the practices that he describes of discovering and following fashion trends, evidenced by the rather luxurious content of his wardrobe, imply that he indeed is an 'instinctively' fashionable man, who can sense 
emerging trends based on his experience. So he is 'in tune' with fashion as opposed to being a 'fashionable man' who blindly follows trends, which also links to the scripts of hegemonic masculinity he might recall from his past of an active and creatively attuned to changing trends individual.

In the following extract, another participant, Grahame (61) reflects on his highly intuitive way of learning about fashion trends by looking at others around him:

It's just there, you know, and you don't really need to be told that something's in fashion. You just spot it, early, that you might just see one person and you think 'Wow! That's cool'. [...] So when [I was asked] to do this [being interviewed], [...] I wouldn't have put myself down as somebody who was, sort of, like 'into fashion'. Because it has always been there - it's just me.

There are two striking similarities between Ian's and Grahame's accounts. Like Ian, Grahame draws a picture of an individual who throughout his life has developed an instinctual ability to detect and discover upcoming fashion trends. Like Ian, he also resists being categorized as a man who is 'into fashion'. This may suggest that he does not want to be associated with vanity or narcissism, however, when we look at the passage as a whole, once again a tension emerges between what Grahame does and how he describes himself that we suggest is caused by the gender and youth connotations of the term 'fashion' (Kaiser 2012; Twigg 2013a).

So far in this article, we have looked at the practice of discovering and following emerging fashion trends as evidence of an individual's engagement with fashion. Now, we will turn our attention to the practice of buying fashionable clothing, which we argue shows unequivocally an individual's engagement with fashion. After all, the commercial dimension of the fashion system exists only through producing, advertising and selling various goods (Wilson 1985). While in this study the primary focus was placed upon psychological aspects of engaging with fashion and clothing, rather than its economic facet, it is possible to see the practices of spending money and buying fashionable clothing as prime instances of our participants' active engagement with fashion. In the following extract, Kevin (63) explains how shopping for clothing gives him an opportunity to find and buy clothes allowing for the creation of a personally important distinctive and tasteful look:

I certainly don't subscribe to the idea of looking ridiculous for the sake of fashion um... but I think you can look distinctive simply through having good taste and bringing the right clothes together. [...] it makes me feel more confident. It makes me feel good about myself. [...] and it's fun. It's still fun. I still like shopping for clothes and finding something a little bit different. [...][and] I say the happiest time... in terms of wearing clothes since then [1960s] is now. I'm really er... I like the clothes that I've got and I like the way that I feel wearing them.

In looking at this extract as a whole, we cannot escape from the impression that, similar to other participants, Kevin also distances himself from being recognized as an individual overtly interested in fashion. Likewise, he acknowledges the importance of finding the balance between looking 'distinctive' and 'ridiculous'. However, at the same time, Kevin emphasizes the fun element embedded within this somewhat creative practice of 'finding something a little 
bit different'. This implies a particular complexity in Kevin's relationship to fashion. On the one hand, he clearly attempts to create a vision of a man who does not wear standard clothing like others around him, who values being distinctive and different as expressed in his clothing selection, perhaps even rebel against the dominant cultural scripts (Bovone 2012). On the other hand, Kevin seems to avoid stretching the boundaries of this 'distinctiveness' too far, to not lose the control over how unique and different to others he appears, without subverting those scripts.

But what is also compelling in this extract is that Kevin identifies this precise time of his life, at the age of 63 , as the second happiest time when it comes to clothing; it is only the period of the 1960s that Kevin classifies as more satisfactory. This, we argue, could be linked to the fact that this particular period in British history is connected with a certain socio-cultural ferment when young people achieved a certain degree of freedom in relation to their clothing (Hebdidge 1979). Furthermore, it can be argued that nowadays Kevin might experience a similar degree of freedom. As an individual, he has a stabilized personal situation as well as professional position, which might be affecting him feeling 'relaxed' enough about the clothes he chooses to wear, to simply enjoy engaging with fashion. Significantly, the years of collecting highquality clothing, to which he refers elsewhere in his interview, allowed him to generate enormous clothing resources to select from. All of these points might influence this 'relaxed' state when Kevin enjoys his daily encounters with his clothing and finds pleasure in wearing them.

In this section, we have looked at the potential disengagement between male ageing and fashion, concentrating on two sets of practices central to men's active encounters with fashionable clothing, namely discovering and following fashion trends and buying and wearing clothes, practices that stereotypically could be perceived as non-masculine. As the interview extracts show, the participants in this study displayed a high level of engagement with all these practices. They reported learning about emerging fashion trends via various channels including reading men's fashion magazines, such as GQ or Esquire. Additionally, they all identified having a certain level of instinctual fashion awareness as a unique characteristic, which distinguished them from others around them. Similarly, they associated buying and wearing clothes with pleasure and fun and described them as practices that they simply enjoy engaging with.

None of the participants displayed any level of withdrawal from such practices purely on the basis of their age. In contrast, the participants presented their lifelong interests in fashion as something that they have developed and celebrated throughout their life course and that is an inherent element of their lives. However, this is not to say that their personal experiences and relationships with fashion as individuals can be simplified in this sense. Instead, these participants in their narratives displayed various tensions and contradictions in relation to fashion - 'being into fashion' and 'being fashionable' were particularly problematic. For these reasons, we argue that while this fraction of older British men does not fall into the stereotypical assumption of older men being disengaged from fashion, it is these individuals themselves who may attempt to superficially reproduce this disengagement. We interpret such attempts as the participants feeling constrained by enduring stereotypical presumptions about fashion, and consequently, their pursuit of reinforcing the connections with the contemporary norms of hegemonic masculinity, norms from which they might feel increasingly excluded as they grow older (Spector-Mersel 2006), but also the past scripts they recall as reproduced by their fathers who less actively 
engaged with fashion, and ironically, ones the participants rebelled against. The consequence of this is that while their freedom to engage with fashionable clothing is enhanced as they age, they might simply avoid admitting it.

\section{Discussion and conclusion}

There is a relative lack of literature on older straight men and their relationship(s) with fashion, which is despite the recent academic attempts to expand fashion scholarship and include men alongside women as subjects of its interest. Although fashion scholarship increasingly turns to men and masculinities, its prime focus seems to be on younger and/or gay men. Similarly, ageing studies, when rarely relating to fashion and clothing, also tend to focus on the somewhat 'disadvantaged' position of older women (Leontowitsch 2012), neglecting older men and their mature masculinities (Sadkowska et al. 2015). This, as we identified, is the consequence of the rather complicated status of fashion as a cultural field.

Fashion is stereotypically assumed to be a feminine domain, with its discourses only recently expanding to include some groups of men. Additionally, since the 1960s and the development of 'youth culture' intensified by the prominence of various subcultures, fashion is understood as a field exclusively reserved to young people (Barnard 2002). This excludes opinions from older men, who are assumed to be disengaged from fashion as a cultural sphere on the basis of the intersection of their gender and mature age. Consequently, in this article, we have challenged these stereotypical assumptions by juxtaposing them with a body of research material stemming from in-depth, semi-structured interviews and personal inventories with a small sample of British men in their 50s and 60s with a lifelong interest in fashion. Furthermore, due to certain difficulties in unequivocal explanation of the term fashion per se, we have adopted an approach where individuals' engagement with fashionable clothing can be taken as material evidence for their engagement with fashion (Klepp and Bjerck 2014). We presented our findings in regards to two types of potential disengagement, between men and fashion and between fashion and ageing, and analysed them in regards to the Connell's (2005) influential concept of hegemonic masculinity.

As the presented narratives show, the men in this study exhibit strong interest in fashion as manifested by their engagement with clothing. Firstly, all participants perceived themselves as unique entities who developed their fashion awareness as early as their childhood, the skill that has accompanied them into their mature and older years. At the same time, however, they valued their shared, generational identity as men who grew up in the 1960s Britain, were members of various subcultures, witnessing and participating in various socio-cultural changes, including modern developments in fashion and, more pertinently, in menswear (Sadkowska et al. 2015). This sense of a generational pioneering in regards to fashionable clothing was carried into the participants' adulthood and consequently into their older age, therefore contradicting their potential disengagement with fashion based on male gender. Furthermore, the participants in this study were responsive to the social and cultural expectations of gender and age as they might recall from their past, consequently, embodying past and present meanings of hegemonic masculinity reflecting the socio-cultural dynamics of their life course (Spector-Mersel 2006).

To add to this, our participants' narratives often related to the practices of discovering and following fashion trends as well as shopping for and buying 
fashionable clothing, stereotypically non-masculine practices. However, the significance of this for each participant lies in the sense of being a unique individual, 'talented' in the direction of fashion - our participants described their instinctual ability to detect upcoming fashion trends, skills that have been honed and embedded within who they have become. Likewise, the practice of shopping for fashionable clothing was described as a form of pleasure and enjoyment. This clearly contradicts the idea that older men might withdraw from active engagement with fashion due to their age, but also frames the concept of hegemonic masculinity as a context-dependent and ever changing and developing 'configuration[s] of practice[s]' (Connell 2005: 44). And while Meadows and Davidson (2006) explain ageing in terms of the transition from workplace to home space and from production to consumption, which they argue can bring men closer to notions typically perceived as feminine, our participants' consumption of fashion was reflective of their lifelong self-negotiation between changing cultural scripts of masculinities and femininities, likewise maturing and growing old.

However, while it is clear that the older male participants in this study do actively engage with fashionable clothing on a daily basis, it is not without certain tensions and contradictions, as displayed in their narratives. All of the men in this study distanced themselves from being described as 'fashionable', as well as the term 'fashion' per se. For this reason, we argue, that our participants attempted to superficially reinforce such a stereotypical disengagement, and while they are actively challenging and disrupting the contemporary social scripts of men and masculinities, they simultaneously reinforce them; for the men in this study, inscriptions and resistance to those inscriptions are consolidated within who they are (Spector-Mersel 2006). Effectively, these individuals are simultaneously responsive to different scripts of hegemonic masculinity: ones that they might recall from their past, championed by their unfashionable/old-fashioned fathers; ones, they materialized through their lives as young men in the 1960s onwards, i.e. fashion rebels; and the present-day ones, represented by younger generation who openly and actively engage with fashion.

Consequently, escaping from being categorized as a 'fashionable man' afforded the participants the opportunities to more freely engage with clothing, without being subject to social judgment or critique regarding their gender or age - as individuals and stylish men, not'older men'/'no longer young men' per se. Furthermore, this tells us about where the participants in this study perceive themselves within the hierarchy of the fashion system, i.e. their clothing choices are not dictated or determined by fashion trends, instead fashionable clothing is integral to their manifestations of who they are. In this, our participants consider themselves as collaborators with fashion who exercise their own agency, not blind followers who are submissive to the tastes of others, continuing to materializing the contemporary Western scripts of hegemonic masculinities within the fashion context.

Finally, the evidence we have set out of the complex nature of our participants' relationship with and disengagement with fashion is in line with Twigg's (2013b) suggestion that there is a pervasive tendency of 'moving younger' within the contemporary fashion dynamics. This is evidenced in phrases such as 'sixty is new fifty/forty', through to retailers' persistent attempts to create an illusion that the goods are aimed at customers younger than they really are and, finally, to the way that various, not necessarily young, fashion styles are diffused with society. While Twigg's reasoning applies mostly to the relation between fashion industry and older women, it suggests the interesting 
question of how this 'moving younger' trend functions in regards to men's fashion, and whether the shifts in men's relationship to fashion is a response to these phenomena, or if these move by the fashion retail industry are a response to changes in older men's self-image and identity. While in this article we are unable to unequivocally answer these questions, we recognize the need for further work linking male ageing and fashion, and especially in relation to older men's consumption of fashionable clothing.

\section{REFERENCES}

Arnold, R. (2001), Fashion, Desire and Anxiety: Image and Morality in the 20th Century, London: I. B. Tauris.

Barnard, M. (2002), Fashion as Communication, 2nd ed., London: Routledge.

Beynon, J. (2002), Masculinities and Culture, Buckingham, UK: Open University Press.

Bovone, L. (2012), 'Fashion, identity and social actors', in A. González and L. Bovone (eds), Identities Through Fashion: A Multidisciplinary Approach, London: Bloomsbury, pp. 67-93.

Breward, C. (2010), 'Modes of manliness: Reflection on recent histories of masculinities and fashion', in G. Riello and P. McNeil (eds), The Fashion History Reader: Global Perspectives, London: Routledge, pp. 301-07.

Buchbinder, D. (1994), Masculinities and Identities, Melbourne: Melbourne University Press. (2012), Studying Men and Masculinities, New York: Routledge.

Calasanti, T. M. and Slevin, K. F. (2006), 'Introduction', in T. M. Calasanti and K. F. Slevin (eds), Age Matters: Realigning Feminist Thinking, London: Routledge, pp. 1-17.

Chrisler, J. C. and Ghiz, L. (1993), 'Body image issues of older women', in N. D. Davis, E. Cole and E. D. Rothblum (eds), Faces of Women and Aging, Harrington, UK: Haworth Press, pp. 67-78.

Church Gibson, P. (2000), 'No-one expects me anywhere', in S. Bruzzi and P. Church Gibson (eds), Fashion Cultures: Theories, Explorations and Analysis, London: Routledge, pp. 79-89.

Cole, S. (2000), 'Don We Now Our Gay Apparel': Gay Men's Dress in the Twentieth Century, Oxford, UK: Berg.

Connell, R. W. (2005), Masculinities, 2nd ed., Cambridge, UK: Polity Press.

Cornwall, A. and Lindisfarne, N. (1994), 'Dislocating masculinity: Gender, power and anthropology', in A. Cornwall and N. Lindisfarne (eds), Dislocating Masculinity: Comparative Ethnographies, London: Routledge.

Crane, D. (2012), 'Introduction', in A. González and L. Bovone (eds), Identities Through Fashion: A Multidisciplinary Approach, London: Bloomsbury, pp. 1-6.

Davis, K. (2002), '"A dubious equality": Men, women and cosmetic surgery', Body Society, 8:1, pp. 49-65.

Edwards, T. (1997), Men in the Mirror: Men's Fashion, Masculinity and Consumer Society, London: Cassell.

- (2006), Cultures of Masculinity, London: Routledge.

(2011), 'The clothes maketh the man: Masculinity, the suit and men's fashion', in T. Edwards (ed.), Fashion in Focus: Concepts, Practices and Politics, London: Routledge, pp. 41-64.

Entwistle, J. (2000), The Fashioned Body, Cambridge, UK: Polity Press.

Fairhurst, E. (1998), "'Growing old gracefully" as opposed to"mutton dressed as lamb": The social construction of recognizing older women', in S. Nettleton (ed.), Body in Everyday Life, Florence, Italy: Routledge, pp. 258-75. 
Gibson, P. C. (2000), 'No-one expects me anywhere', in S. Bruzzi and P. Church Gibson (eds), Fashion Cultures: Theories, Explorations and Analysis, London: Routledge, pp. 79-89.

Gilleard, C. and Higgs, P. (2000), Cultures of Ageing: Self, Citizen and the Body, London: Prentice Hall.

(2005), Contexts of Ageing: Class, Cohort and Community, Malden, MA: Polity Press.

Hall, S. and Jefferson, T. (eds) (1976), Resistance Through Rituals: Youth Subcultures in Post-War Britain, Birmingham, UK: The Centre for Contemporary Cultural Studies.

Hearn, J. (1995), 'Imaging the aging of men', in M. Featherstone and A. Wernick (eds), Images of Aging: Cultural Representations of Later Life, London: Routledge, pp. 97-115.

Hebdidge, D. (1979), Subculture: The Meaning of Style, London: Methuen.

Hollander, A. (1994), Sex and Suits: The Evolution of Modern Dress, Brinkworth, UK: Claridge Press.

Hurd Clarke, L., Griffin, M. and Maliha, K. (2009), 'Bat wings, and Turkey wattles: Body transgressions and older women's strategic clothing choices', Ageing and Society, 29:5, pp. 709-26.

Kaiser, S. (2012), Fashion and Cultural Studies, London: Berg.

Kaiser, S., Looysen, R. and Hethorn, J. (2008), 'Unmasking hegemonic masculine fashion on the politics of cultural (in)visibility', Proceedings, Gender Conference, Boston, MA, June, pp. 188-210.

Kawamura, Y. (2011), Doing Research in Fashion and Dress, Oxford, UK: Berg.

Kimmel, M. (1994), 'Masculinity as homophobia: Fear, shame and silence in the constructions of gender identity', in H. Brod and M. Kaufman (eds), Theorizing Masculinities, Thousand Oaks, CA: Sage, pp. 119-41.

Klepp, I. G. and Bjerck, M. (2014), 'A methodological approach to the materiality of clothing: Wardrobe studies', International Journal of Social Research Methodology, 17:4, pp. 373-86.

Leontowitsch, M. (2012), 'Interviewing older men', in M. Leontowitsch (ed.), Researching Later Life and Ageing: Expanding Qualitative Research Horizons, Basingstoke, UK: Palgrave Macmillan, pp. 104-23.

Lurie, A. (1992), The Language of Clothes, London: Bloomsbury.

McNeil, P. and Karaminas, V. (eds) (2009), The Men's Fashion Reader, Oxford, UK: Berg.

Meadows, R. and Davidson, K. (2006), 'Maintaining manliness in later life: Hegemonic masculinities and emphasized femininities', in T. M. Calasanti and K. F. Slevin (eds), Age Matters: Realigning Feminist Thinking, London: Routledge, pp. 295-312.

UK Office for National Statistics (2011), 'Statistical bulletin: Births and Deaths in England and Wales', http://www.ons.gov.uk/ons/rel/vsob1/ birth-summarytables--england-andwales/2011-final-/sb-births-anddeathsin-england-andwales-2011-final-.html\#tab-Key-trendsin-birthsand-deaths--numbers-and-rates. Accessed 7 December 2012.

Pringle, R. (2005), 'Masculinities, sport, and power: A critical comparison of Gramscian and Foucauldian inspired theoretical tools', Journal of Sport and Social Issues, 29:3, pp. 256-78.

Reilly, A. and Cosbey, S. (eds) (2008), Men's Fashion Reader, Oxford, UK: Berg.

Ricciardelli, R., Clow, K. and White, P. (2010), 'Investigating hegemonic masculinity: Portrayals of masculinity in men's lifestyle magazines', Sex Roles, 63:1\&2, pp. 64-78. 
Sadkowska, A. (2016), 'Arts-informed interpretative phenomenological analysis: Understanding older men's experiences of ageing through the lens of fashion and clothing', Unpublished Ph.D. thesis, Nottingham, UK: Nottingham Trent University.

Sadkowska, A., Wilde, D. and Fisher, T. (2015), 'Third age men's experience of fashion and clothing: An interpretative phenomenological analysis', Age, Culture, Humanities: An Interdisciplinary Journal, 2:1, pp. 33-68.

Smith, J. A., Flowers, P. and Larkin, M. (2009), Interpretative Phenomenological Analysis: Theory, Method and Research, London: Sage.

Spector-Mersel, G. (2006), Never-aging stories: Western hegemonic masculinity scripts', Journal of Gender Studies, 15:1, pp. 67-82.

Steele, V. (2000), 'Fashioning men', in G. Malossi (ed.), Material Man: Masculinity, Sexuality, Style, New York: Harry N. Abrams, pp. 78-83. (2005), 'Letter from the editor', Fashion Theory, 9:1, pp. 1-2.

Townsend, K., Sadkowska, A. and Sissons, J. (2016), 'Emotional Fit: Developing a new fashion design methodology for mature women', Proceedings of the Design Research Society (DRS) Future-Focused Thinking Conference, Brighton, 27-30 June, https://static1.squarespace.com/ static/55ca3eafe4b05bb65abd54ff/t/5749894960b5e9b0a773c19a/14644370 69936/422+Townsend.pdf. Accessed 24 October 2016.

Twigg, J. (2007), 'Clothing, age and the body: A critical review', Ageing and Society, 27:2, pp. 285-305.

_ (2013a), Fashion and Age: Dress, the Body and Later Life, London: Bloomsbury.

(2013b), 'Fashion, the body, and age', in S. Black, A. De La Haye, J. Entwistle, A. Racamora, R. Root and H. Thomas (eds), The Handbook of Fashion Studies, London: Bloomsbury, pp. 78-94.

Wilson, E. (1985), Adorned in Dreams: Fashion and Modernity, London: Virago.

\section{SUGGESTED CITATION}

Sadkowska, A., Townsend, K., Fisher, T. and Wilde, D. (2017), '(Dis-)engaged older men? Hegemonic masculinity, fashion and ageing', Clothing Cultures, 4:3, pp. 185-201, doi: 10.1386/cc.4.3.185_1

\section{CONTRIBUTOR DETAILS}

Dr Ania Sadkowska is a fashion designer, lecturer and researcher at Coventry University, UK. In the past, she worked as a lecturer and research fellow at Nottingham Trent University, UK. Her research explores the intersection of sociology and psychology with art and design practices. Current projects span a variety of topics, including fashion and ageing, masculinity, phenomenology and art and design research methodologies. Ania has presented work at various UK and international conferences and exhibitions, including in Italy, China, Sweden and the US. Recently, her research paper has been published in Age, Culture, Humanities: An Interdisciplinary Journal (special issue on Fashion and Ageing). Since 2014, she has been involved in a co-creative research project titled 'Emotional Fit: Developing a new fashion methodology with older women'.

Contact: School of Art and Design, Coventry University, Priory Street, Coventry CV1 5FB, UK.

E-mail: ac3739@coventry.ac.uk 
Dr Katherine Townsend is an associate professor in fashion and textile crafts in the School of Art and Design at Nottingham Trent University. Her current research projects, 'Emotional Fit: Developing a new fashion methodology with mature women' and 'The electric corset and other future histories', explore material and cultural issues in fashion, textiles and ageing and the use of costume archives to inform the design of e-textiles and wearables. Her research into the role of embodied knowledge in the digital crafting of textiles was recently published in the chapter 'Closely held secrets', in Crafting Textiles in the Digital Age (Bloomsbury 2016). She is co-editor of the journal Craft Research.

Contact: School of Art and Design, Nottingham Trent University, 50 Shakespeare Street, Nottingham NG1 4FQ, UK.

E-mail: katherine.townsend@ntu.ac.uk

Tom Fisher is a professor in the School of Art and Design at Nottingham Trent University. His work draws on his background in craft practice and stresses the materiality of our interactions with things, and therefore their design. It has led to a book on the everyday reuse of packaging (Designing for Re-Use, Earthscan, 2009), a recent special issue of the Journal of Design History on the meaning of materials' surface qualities, a special issue of Critical Studies of Fashion and Beauty on fashion and materiality and a 2017 book for Gower, Design for Personalisation. He has led funded research on sustainable clothing (Defra) and industrial heritage (AHRC). His current work focuses on embodied knowledge; the ethics of design and technologies; and design, culture and innovation.

Contact: School of Art and Design, Nottingham Trent University, 50 Shakespeare Street, Nottingham NG1 4FQ, UK.

E-mail: tom.fisher@ntu.ac.uk

David Wilde is a senior lecturer at Nottingham Trent University. He graduated from the University of Sunderland with a degree in psychology with human physiology in 1996 and, the following year, obtained an M.Sc. in environmental psychology from the University of Surrey. After working as an environmental psychologist for three years, he began working in the field of cancer and palliative care at the University of Sheffield. In 2005, he attained a Diploma in consciousness and transpersonal psychology from Liverpool John Moore's University. In the same year, he joined the University of Manchester where he obtained his Ph.D. in 2011. He returned to the cancer and palliative care field whilst working at the University of Huddersfield for two years. David's research interests cover out-of-body and near-death experiences, anomalous experiences and mental health, cancer, palliative care and long-term conditions and patient and public involvement in research.

Contact: School of Art and Design, Nottingham Trent University, 50 Shakespeare Street, Nottingham NG1 4FQ, UK.

E-mail: david.wilde@ntu.ac.uk

Ania Sadkowska, Katherine Townsend, Tom Fisher and David Wilde have asserted their rights under the Copyright, Designs and Patents Act, 1988, to be identified as the authors of this work in the format that was submitted to Intellect Ltd. 